\title{
Exploring socio-contextual factors associated with male smoker's intention to quit smoking
}

Minsoo Jung

\begin{abstract}
Background: Programs to encourage smokers to quit smoking tobacco have been implemented worldwide and are generally viewed as an effective public health intervention program. However, few studies have examined the social factors that influence a smoker's intention to quit smoking. This study investigated the socio-contextual factors that are associated with the intention to quit smoking among male smokers in South Korea.

Methods: Data were obtained from a 2014 nationally representative panel that examined the influences of mass media on the health of the Korean population. Members of this panel were recruited using a mixed-method sampling and a combination of random digit dial and address-based sampling designs. Survey questions were based on those used in previous studies that assessed the effects of social context, including mass media and social capital, on health. Multivariate logistic regression analyses of the answers of 313 male smokers were undertaken.

Results: Male smokers who participated in community-based activities were 2.45 times more likely to intend to quit smoking compared to male smokers in general (95\% confidence interval [Cl]: 1.25-6.82). In addition, male smokers who participated in informal social gathering networks were 2.38 times more likely to intend to quit smoking compared to male smokers in general $(95 \% \mathrm{Cl}$ : 1.11-5.10). Moreover, male smokers with high smartphone use were 1.93 times more likely than smokers with low smartphone use to intend to quit smoking within one year (95\% Cl: 1.07-3.46).

Conclusions: A supportive environment that enables male smokers to access beneficial health information and that encourages them to quit smoking is necessary for a stop-smoking program to be effective. The result of this study contribute to establishing a new smoking control policy by identifying socio-contextual factors related to the intention to quit smoking.
\end{abstract}

Keywords: Quit smoking, Health communication, Media exposure, Socioeconomic position

\section{Background}

Many developed countries have implemented multifaceted anti-smoking policies in the twenty-first century that include price- and non-price-based approaches to lowering tobacco smoking (henceforth, smoking) rates [1]. The decrease in smoking rate in many developed countries has slowed down, and the changes in smoking rate in some countries are stagnant [2]. In particular, a high smoking rate among male smokers is a reason for the stable prevalence of adult smoking in Asian

Correspondence: mins.jung@gmail.com

Department of Health Science, Dongduk Women's University, 23-1

Wolgok-dong, Seongbuk-gu, Seoul 136-714, South Korea countries. In 2012, adult smoking rates in China, Japan and South Korea (henceforth, Korea) were 49.0, 36.6 and $43.7 \%$, respectively [3]. The smoking rate among adult Korean males in 2008 was $40.9 \%$ and was $43.1 \% 2013$ [4]. Therefore, the change smoking rate in Korea has stagnated, and encouraging smoking cessation in male smokers is important.

Price-based policies have been implemented in Korea eight times between 1986, when tobacco advertising was restricted through the Tobacco Business Act, and December 2014 [5]. Since 2005, approximately 253 healthcare centers in Korea have been operating smoking cessation clinics. In addition, local governments have 
discouraged smoking by establishing community level smoke-free regulations and declaring smokeless areas [5]. The use of graphic warning labels, which were first introduced in Canada in 2001 and are now used globally [6], was approved by Korean National Assembly standing committee in accordance with the World Health Organization Framework Convention on Tobacco Control. Regardless, Korea, with the highest smoking rate among Organization for Economic Co-operation and Development countries, is attempting to develop more effective anti-smoking policies. Other East-Asia countries, such as China and Japan, have a similar problem with stagnant smoking rates, which has been attributed to their similar societal, behavioral and cultural views on smoking $[7,8]$.

The trans-theoretical model (TTM) regarding behavioral change can be used to explain the process of change that smokers go through to succeed in quitting smoking. Such modelling has been widely used to investigate change-positive behaviors [9]. According to the TTM, a smoker goes through pre-contemplation, contemplation, preparation, action and maintenance stages when quitting smoking $[10,11]$. A critical factor in attaining these stages of behavioral change is the smoker's intention to quit smoking [12-15]. This is because the TTM is a helical process with the capacity for repeated entrance and regression rather than a process with unidirectional progression. Among the TTM constructs, the intention to quit smoking before quitting has been suggested to be a predictor of whether the smoker will participate in a smoking cessation program, attempt to quit smoking and succeed in quitting $[14,16,17]$. Therefore, when developing various quitting-smoking programs, developed countries have conducted studies on socio-demographic and smokingrelated factors that affect participants' intentions, attempts and successes when quitting smoking $[15,18]$.

However, smokers in the preparatory stage of a behavioral change do not easily show a behavioral change despite having a greater level of intention that that of smokers in the contemplation stage [19]. Therefore, the main factors affecting the intention to quit smoking need to be determined for smokers with little or no intention to quit. Nevertheless, many preceding studies on smoking cessation described the cognitive factors of smokers in different behavioral change stages than those in the TTM model $[13,14,17,20]$. These studies described general, smoking-related and health-related characteristics of smokers during different behavioral change stages [21]. Few studies have reported on factors that influence the intention to quit smoking or whether the attempts were successful $[18,19,22]$. In these studies, the subjects were small groups of young adults, office workers and participants in various healthcare center smoking cessation programs. Hence, the study designs were unsuitable for a nationwide assessment of the various contextual factors that affect a male smoker's intention to quit smoking. This nationwide study examined socio-contextual factors regarding the intention to quit smoking in adult male smokers. We focused on the intention to quit smoking but our TTM model also included several other variables.

\section{Methods}

\section{Study participants}

The data for this study came from a nationally representative sample of Korean adults who participated in Hankook Research's Master Sample Panelఠ. Members of this panel were recruited using a mixed-method sampling frame and a combination of random digit dial and address-based sampling designs, which allows sampling of individuals who do not have a telephone land line. Based on the purpose of this study, male non-smokers and all females were excluded; only male smokers were included $(n=313)$. A survey questionnaire was provided online to participating male smokers. Participants received a nominal cash incentive to participate in the survey, and the final response rate was $87.0 \%$. Survey questions with missing values for key analytical variables were excluded using a pairwise method.

\section{Ethics statement}

Approval for the study was granted by the Korea National Institute for Bioethics Policy Institutional Review Board (April 11, 2014; P01-201404-SB-19-00). All participants gave written informed consent to participate. The Ethics Committees of the Demographic Health Survey approved this consent procedure. Any information that could distinguish individual participants was not collected during the data collection process.

\section{Measures}

The survey questions were based on those used in previous reports on the effects of social context, including mass media use and social capital, on health $[2,10,20$, $22,23]$. The questionnaire included topics adapted from the Health Information National Trends Survey (http://hints.cancer.gov/).

\section{Dependent variables}

This study focused on current male smokers regardless of numbers of cigarettes consumed per day. The outcome variable was the intention of the participant to quit smoking. All self-rated smokers were asked to report their intention to quit smoking on a 5-point scale: (1) "Intends to take action within the next 30 days," (2) "Intends to take action within the next 90 days," (3) "Intends to take action within the next 6 months," (4) "Intends to take action within the next 12 months," and (5) "Has no 
intention to take action within the next 12 months." The initial question was "Do you have an intention to quit smoking?" The answers were grouped into two categories. Participants responding with (5) were coded as 0 and grouped as no intention to quit smoking. Those responding with (1-4) were coded as 1 and were grouped as intending to quit smoking.

\section{Independent variables}

Participant's socio-economic position was based on education and annual household income levels. Participants were asked to identify their highest education degree earned: high school diploma or less; college degree; or postgraduate degree. Participants were asked to report their total annual household income before taxes: < USD 20,000; USD 20,000-39,999; USD 40,000-59,999; USD 60,000-79,999; and USD $\geq 80,000$. General mass media usage was assessed by the following questions: "In the past 7 days, how many hours do you: watch television per day on average; listen to the radio; read a newspaper; search information with a smartphone; and read news on the Internet with a personal computer?" The response range was 0 to $\geq 5 \mathrm{~h}$. We asked seven questions about barriers to finding desired healthrelated information. For each question, participants were asked to note whether there was a large problem, small problem or no problem at all when trying to obtain the desired information about their health.

We conducted a principal components analysis (PCA) to reduce the number of study variables and detect the internal variance structure in the relationships between variables. The PCA factors used to construct the information barrier index presented eigenvalues $>1$ and factor loadings $>0.40$. The first factor, "information access barriers", accounted for $32.4 \%$ of total variance (Cronbach's alpha $=0.73$ ). This factor included three of the seven barriers: "access to the Internet; difficulties using an on-line search tool or software; and the available information used too many technical terms". A second factor, "information utilization barriers", explained $26.4 \%$ of total variance. This factor included the remaining four potential barriers: too much information; no way to tell if the information was accurate; no way to tell if the information was up-to-date; and no way to tell if the information was relevant to my situation. These factors were used to define a reverse scale for accessing individual capacity to access health information. A low alpha value of 0.5 indicated that the question did not have a unidimensional scale. In this study, an alpha value of 0.7 indicated that the question was acceptable for use as a measurement scale [24].

\section{Potential confounders}

Participants were asked to rate their own general health status on a 5-point Likert-type scale ranging from very good to very bad. The initial question was "How is your health in general?" The answers were eventually grouped into two categories. Participants reporting "very bad," "bad," or "average" for self-rated health (SRH) status were coded as 0 and were placed in the low-SRH group, whereas those reporting "very good" or "good" SRH status were coded as 1 and were placed in the high-SRH group. We also asked about outpatient visits, including dental and oriental medicine treatments during the month preceding the questionnaire. The responses were grouped into two categories of yes or no. In addition, we asked seven questions related to social capital to determine the degree of community social cohesion. Social capital included social structural features, such as interpersonal trust and norms of reciprocity and mutual aid that act as resources for individuals and facilitate collective social action [25]. Social capital thus forms a subset of the features of social cohesion. Participants were asked to note whether they "actively participated, participated, just joined or not involved at all in social gatherings in their community or by personal membership" for each social issue. After conducting the PCA, we detected two factors associated with the greatest proportion of the total variance. The first factor, "community-based activities", accounted for $28.8 \%$ of total variance (Cronbach's alpha $=0.70)$ and included four community activities: workplace, neighborhood, volunteer and political activities. The second factor, "informal social gathering", was associated with $22.5 \%$ of total variance (Cronbach's alpha $=0.64$ ). This factor included the remaining three community activities: informal associations, get-together club and religious group activities.

\section{Statistical analyses}

First, descriptive statistics and frequencies were derived for all variables. Second, bivariate analyses were undertaken for each potential predictor variable to identify socio-contextual factors associated with the intention to quit smoking. Barriers to obtaining health-related information or social capital were subjected to factor analyses. Subsequently, differences in the social characteristics between the groups with and without intentions to quit smoking were assessed by the chi-square test. Finally, multivariate logistic regression analyses were used to analyze potentially influential factors related to the intention of adult Korean males to quit smoking. All analyses were conducted using SPSS v.21.0 software (IBM SPSS, Armonk, NY, USA).

\section{Results}

General sample characteristics

Of the 313 male smoker participants, 81 (25.9\%) were in their $40 \mathrm{~s}$ and $33(10.5 \%)$ were $\geq 60$ years of age (Table 1). A total of 214 participants $(68.4 \%)$ had a 
Table 1 General characteristics of the sample, 2014 (male smokers, $n=313$ )

\begin{tabular}{|c|c|c|c|c|c|}
\hline & $n$ & $\%$ & & $n$ & $\%$ \\
\hline Age & & & Television Watching & & \\
\hline $20-29$ & 55 & 17.6 & 30 min or less & 51 & 16.3 \\
\hline $30-39$ & 89 & 28.4 & 30 min to one hour & 47 & 15.0 \\
\hline $40-49$ & 81 & 25.9 & One hour to two hour & 102 & 32.6 \\
\hline $50-59$ & 55 & 17.6 & Two hour to three hour & 65 & 20.8 \\
\hline 60 or older & 33 & 10.5 & Three hour or more & 48 & 15.3 \\
\hline Education & & & Radio Listening & & \\
\hline high school or less & 99 & 31.6 & No listening & 121 & 38.7 \\
\hline college & 178 & 56.9 & 10 min or less & 41 & 13.1 \\
\hline post-graduate & 36 & 11.5 & $10 \mathrm{~min}$ to $30 \mathrm{~min}$ & 55 & 17.6 \\
\hline Income & & & 30 min to one hour & 48 & 15.3 \\
\hline US\$20 K or less & 35 & 11.2 & One hour or more & 48 & 15.3 \\
\hline US\$20 K-40 K & 110 & 35.1 & Newspaper Reading & & \\
\hline US\$40 K-60 K & 97 & 31.0 & No reading & 143 & 45.7 \\
\hline US\$60 K-80 K & 45 & 14.4 & 10 min or less & 46 & 14.7 \\
\hline US\$80 K or more & 26 & 8.3 & $10 \mathrm{~min}$ to $30 \mathrm{~min}$ & 59 & 18.8 \\
\hline $\mathrm{SRH}$ & & & 30 min or more & 65 & 20.8 \\
\hline High SRH & 264 & 84.3 & Smartphone Browsing & & \\
\hline Low SRH & 49 & 15.7 & no use or less than $10 \mathrm{~min}$ & 43 & 13.7 \\
\hline Medical Utilization & & & $10 \mathrm{~min}$ to $30 \mathrm{~min}$ & 51 & 16.3 \\
\hline Never & 161 & 51.4 & 30 min to one hour & 94 & 30.0 \\
\hline One time & 86 & 27.5 & One hour to two hour & 81 & 25.9 \\
\hline Two time & 35 & 11.2 & Two hour or more & 44 & 14.1 \\
\hline Three time or more & 31 & 9.9 & Computer Searching & & \\
\hline Intention to quit smoking & & & No use or less than 10 min & 41 & 13.1 \\
\hline No intention to take action within the next 12 months & 72 & 23.0 & $10 \mathrm{~min}$ to $30 \mathrm{~min}$ & 36 & 11.5 \\
\hline Intends to take action within the next 12 months & 136 & 43.5 & 30 min to one hour & 59 & 18.8 \\
\hline Intends to take action within the next 6 months & 68 & 21.7 & One hour to two hour & 102 & 32.6 \\
\hline Intends to take action within the next 90 days & 14 & 4.5 & Two hour to three hour & 40 & 12.8 \\
\hline Intends to take action within the next 30 days & 23 & 7.3 & Three hour or more & 35 & 11.2 \\
\hline Total & 313 & 100.0 & & 313 & 100.0 \\
\hline
\end{tabular}

college or post-graduate degree, and approximately $35.1 \%$ of all participants earned USD 20,000-USD 40,000 per year. A total of 264 participants (84.3\%) reported high SRH status. With regard to medical utilization and mass media use, 152 participants (48.6\%) had received outpatient care during the month previous to completing the questionnaire, and the two most frequently used sources of mass media were television and smartphone. A total of 215 (68.7 \%) participants watched television $\geq 1 \mathrm{~h}$ per day, and 125 (40.0\%) searched for information via a smartphone. However, only 65 (20.8\%) read newspapers for $\geq 30 \mathrm{~min}$ per day. Seventh-two (23.0\%) participants expressed an intention to quit smoking, and 241 (77 \%) had no intention to quit smoking.
Differences between the groups with and without an intention to quit smoking

The group intending to quit smoking had more participants with a high educational level $(p<0.05)$ and more participants who had received medical service compared to those who did not intend to quit smoking $(p<0.01$, Table 2). More participants who intended to quit smoking read a newspaper than those who did not $(p<0.01)$.

\section{Socio-contextual factors of the intention of smokers to quit smoking}

After controlling for potential covariates, male smokers $\geq 60$ were 1.90 times more likely to intend to 
Table 2 Bivariate analyses of the differences between the smoking and quit smoking groups, 2014

\begin{tabular}{|c|c|c|c|c|c|c|c|}
\hline & $\begin{array}{l}\text { Smoking } \\
(n=208)\end{array}$ & $\begin{array}{l}\text { Intention to } \\
\text { quit smoking } \\
(n=105)\end{array}$ & $p$-value & & $\begin{array}{l}\text { Smoking } \\
(n=208)\end{array}$ & $\begin{array}{l}\text { Intention to } \\
\text { quit smoking } \\
(n=105)\end{array}$ & $p$-value \\
\hline Age & & & & Television Watching & & & \\
\hline $20-29$ & 63.6 & 36.4 & ns & 30 min or less & 66.7 & 33.3 & ns \\
\hline $30-39$ & 67.4 & 32.6 & & 30 min to one hour & 66.0 & 34.0 & \\
\hline $40-49$ & 61.7 & 38.3 & & one hour to two hour & 68.6 & 31.4 & \\
\hline $50-59$ & 72.7 & 27.3 & & two hour to three hour & 67.7 & 32.3 & \\
\hline 60 or older & 69.7 & 30.3 & & three hour or more & 60.4 & 39.6 & \\
\hline Education & & & & Radio Listening & & & \\
\hline High school or less & 76.8 & 23.2 & $<0.05$ & no listening & 74.4 & 25.6 & ns \\
\hline College & 61.2 & 38.8 & & 10 min or less & 65.9 & 34.1 & \\
\hline Post-graduate & 63.9 & 36.1 & & $10 \mathrm{~min}$ to $30 \mathrm{~min}$ & 63.6 & 36.4 & \\
\hline Income & & & & 30 min to one hour & 58.3 & 41.7 & \\
\hline US\$20 K or less & 74.3 & 25.7 & ns & one hour or more & 58.3 & 41.7 & \\
\hline US\$20 K-40 K & 66.4 & 33.6 & & Newspaper Reading & & & \\
\hline US\$40 K-60 K & 68.0 & 32.0 & & no reading & 76.2 & 23.8 & $<0.01$ \\
\hline US\$60 K-80 K & 68.9 & 31.1 & & 10 min or less & 60.9 & 39.1 & \\
\hline US\$80 K or more & 46.2 & 53.8 & & $10 \mathrm{~min}$ to $30 \mathrm{~min}$ & 54.2 & 45.8 & \\
\hline $\mathrm{SRH}$ & & & & 30 min or more & 60.0 & 40.0 & \\
\hline High SRH & 65.9 & 34.1 & ns & Smartphone Browsing & & & \\
\hline Low SRH & 69.4 & 30.6 & & no use or less than $10 \mathrm{~min}$ & 79.1 & 20.9 & ns \\
\hline Medical Utilization & & & & $10 \mathrm{~min}$ to $30 \mathrm{~min}$ & 70.6 & 29.4 & \\
\hline Never & 72.0 & 28.0 & $<0.01$ & 30 min to one hour & 60.6 & 39.4 & \\
\hline One time & 68.6 & 31.4 & & one hour to two hour & 61.7 & 38.3 & \\
\hline Two time & 45.7 & 54.3 & & two hour or more & 70.5 & 29.5 & \\
\hline \multirow[t]{7}{*}{ Three time or more } & 54.8 & 45.2 & & Computer Searching & & & \\
\hline & & & & no use or less than $10 \mathrm{~min}$ & 78.0 & 22.0 & ns \\
\hline & & & & $10 \mathrm{~min}$ to $30 \mathrm{~min}$ & 75.0 & 25.0 & \\
\hline & & & & 30 min to one hour & 59.3 & 40.7 & \\
\hline & & & & one hour to two hour & 64.7 & 35.3 & \\
\hline & & & & two hour to three hour & 65.0 & 35.0 & \\
\hline & & & & three hour or more & 62.9 & 37.1 & \\
\hline
\end{tabular}

ns not significant

quit smoking than young male smokers (95\% confidence interval [CI]: 1.06-3.34) (Table 3). Males who participated in community-based activities were 2.45 times more likely to intend to quit smoking than male smokers who did not participate in community-based activities (95\% CI: 1.25-6.82). Similarly, males who had informal social gathering networks were 2.38 times more likely to intend to quit smoking than males who did not participate in formal social gathering networks $(95 \% \mathrm{CI}$ : 1.11-5.10). No differences in information utilization or access were observed between the groups with and without the intention to quit smoking. However, mass media usage was associated with smokers who intended to quit smoking. After controlling for significant covariates, male smokers who used a smartphone were 1.93 times more likely to have an intention to quit smoking than male smokers who did not use a smartphone (95 \% CI: 1.07-3.46).

\section{Discussion}

Programs to encourage smokers to quit smoking tobacco have been implemented worldwide, and are generally viewed as an effective form of public health intervention. However, few studies have examined the socio-contextual factors that affect the intention to quit smoking in adult 
Table 3 Adjusted odds ratio and $95 \%$ confidence intervals for male smokers who intended to quit smoking within a year, 2014 ( $n=313$ )

\begin{tabular}{|c|c|c|c|c|c|}
\hline & & \multirow[t]{2}{*}{$\mathrm{aOR}$} & \multicolumn{2}{|c|}{$95 \% \mathrm{Cl}$} & \multirow[t]{2}{*}{$p$-value } \\
\hline & & & Lower & Upper & \\
\hline \multirow[t]{2}{*}{ Socioeconomic Position } & Education & 1.706 & 0.574 & 5.068 & ns \\
\hline & Income & 1.201 & 0.715 & 2.017 & ns \\
\hline \multirow[t]{5}{*}{ Health Status } & Age & 1.885 & 1.062 & 3.343 & $<0.05$ \\
\hline & SRH (Ref. = high) & 1.000 & & & \\
\hline & low status & 0.593 & 0.142 & 2.479 & ns \\
\hline & Medical Utilization (Ref. = none) & 1.000 & & & \\
\hline & received outpatient care in the last month & 1.090 & 0.596 & 1.991 & ns \\
\hline \multirow[t]{2}{*}{ Social Capital } & Community-based Activities & 2.453 & 1.249 & 6.823 & $<0.01$ \\
\hline & Informal Social Gathering & 2.378 & 1.110 & 5.096 & $<0.05$ \\
\hline \multirow[t]{2}{*}{ Information-Seeking Capacity } & Utilization Capacity & 0.811 & 0.426 & 1.544 & ns \\
\hline & Access Capacity & 0.677 & 0.305 & 1.502 & ns \\
\hline \multirow[t]{5}{*}{ Media Use } & Television & 0.684 & 0.396 & 1.180 & ns \\
\hline & Radio & 0.923 & 0.606 & 1.404 & ns \\
\hline & Newspaper & 0.965 & 0.579 & 1.610 & ns \\
\hline & Smartphone & 1.927 & 1.074 & 3.458 & $<0.05$ \\
\hline & Computer & 0.947 & 0.595 & 1.507 & ns \\
\hline NagelKerke $\mathrm{R}^{2}$ & & 0.406 & & & \\
\hline
\end{tabular}

Notes: The dependent variable is male smokers who intended to quit smoking within a year: Yes (1) and No (0)

All models are additionally adjusted for sampling region

ns not significant

male smokers. Our results show that Korean adult male smokers who intended to quit smoking have significantly higher levels of social capital and smartphone use than those who did not. Three implications can be drawn from our results.

First, this study shows that a supportive socio-contextual environment, which enables male smokers to access beneficial health information as support while they quit smoking, may be necessary when trying to increase the effectiveness of a smoking cessation program at an individual-smoker level. An individual's intention in the field of health education is important to produce a behavioral change [26, 27]. Although it is possible that, smokers reach out to new networks to get away from their currently smoking peers when intending to quit it is also possible that they weigh the benefits and costs of stopping smoking to evaluate whether their situation is favorable for quitting smoking [11, 27]. The TTM approach attempts to describe an individuals' processes and stages of change associated with behavioral modifications and has been successfully applied in studies of various preventive behaviors [28, 29]. Our TTM results suggest that supportive socio-contextual factors, such as access to health information and beneficial relationships, help to smokers and such factors should be included when applying the TTM approach [30].

Second, the observation that the availability of social capital or a smartphone can affect intention to quit smoking indicates that smoking behavior can be changed through social relationships. As smokers' exposure to health information through social networks or digital devices increases, they have an increasing chance of adopting healthy behaviors [24,31]. Thus, as more friends and acquaintances of smokers stop smoking, the smokers have a greater chance to stop smoking [32]. Social relationships have a strong influence on substance use, and it is well documented that smokers tend to form social relationships with other smokers [33]. In addition, smoking behaviors are significantly associated with socio-economic indicators; for example, it is more difficult to encourage smokers in a lowincome bracket to quit smoking than to encourage highincome bracket smokers to quit. However, smoker's beliefs and attitudes towards specific health issues can be changed through their exposure to mass media [34]. The results of this study suggest a benefit to establishing a smoking control policy that would supply social network services at an interpersonal level.

Third, governments may need to publish and distribute health information through social networks regarding the risks of smoking, as a simple abundance of social capital is insufficient for an effective smoking cessation program [35]. Our results suggest a need to include social capital when developing smoking cessation programs at the community level. Harmful or beneficial health behaviors can spread to others, and the range of such proliferation can be 
substantial [35-37]. Smoking has long been a topic of social controversy over the health risks of tobacco to nonsmokers among a smoker's peers, including secondhand smoke, which is becoming undesirable. When one person stops smoking, a ripple effect can influence the behavior of friends, friends of those friends and so on [36, 37]. In addition, the ripple effect becomes more influential when the group's level of social cohesion is high [38]. Our results show that male smokers who participated in communitybased activities were more likely to intend to quit smoking compared to make smokers in general. In addition, male smokers who participated in informal social gathering networks were more likely to intend to quit smoking compared to male smokers in general. These results suggest that community-based organizations provide support to individuals that would like easy access to information on stopping smoking, particularly via the provision of strategic media advocacy [39].

Several study limitations should be noted. First, a cross-sectional dataset was used; thus, caution is advised when examining potentially causal relationships. Second, not all TTM components were applied in our analysis because our use of the TTM was restricted to health communication factors. Third, the possible presence of heterogeneity in our sample of those who intended to quit smoking needs to be considered, particularly given that those who intended to quit in the next 30 days were grouped with those who intended to quit in the next 12 months. We manipulated the outcome variables in an attempt to consider this heterogeneity; however, the potential effect of such heterogeneity could not be assessed due to the small sample size in our study. The causal relationships inherent in quitting smoking need to be investigated to reduce these limitations. A longitudinal study based on a worldwide national sample is warranted to determine the applicability of our results to other nations. There is also a need to determine the applicability of the present findings to female smokers, both in Korea and abroad.

Despite these limitations, the current study revealed several main factors that affect the intention to quit smoking among adult male smokers who reported little or no intention to quit smoking. Personalized smoking cessation and intervention programs that incorporate socio-contextual factors should be developed. Such programs should assist those intending to quit smoking, help them progress through the stages of quitting smoking, and help those who have just quit smoking overcome abstinence symptoms and enter the nonsmoking maintenance stage.

\section{Conclusions}

Korea adopted a powerful smoking control policy in 2015 that included a significant price increase for tobacco products. The cost of tobacco in Korea had not increased for over a decade. Consequently, many smokers have sincerely considered quitting smoking. Nonetheless, few studies have been conducted to determine the variables that influence a smoker's intention to quit smoking. This study identified socio-contextual factors affecting the intention to quit smoking and may assist in establishing a new smoking control policy. Moreover, our results may influence the design of follow-up studies related to preventing diseases associated with smoking, such as lung cancer and chronic obstructive pulmonary disease.

\section{Ethics}

Approval for the study was granted by the Korea National Institute for Bioethics Policy Institutional Review Board (April 11, 2014; P01-201404-SB-19-00). All participants gave written informed consent to participate. The Ethics Committees of the Demographic Health Survey approved this consent procedure. Any information that could distinguish individual participants was not collected during the data collection process.

\section{Consent to publish}

Not applicable.

\section{Availability of data and materials}

Data sharing: Participant level data are available from the corresponding author.

\section{Abbreviations}

FCTC: framework convention on tobacco control; GWL: graphic warning labels; OECD: Organization for Economic Co-operation and Development: SEP: socio-economic position; SRH: self-rated health; TTM: trans-theoretical model.

Competing interests

The author declares that he has no competing interests.

Author's contributions

MJ conceived the study idea, performed the statistical analysis and drafted the manuscript. MJ advised on methodological issues and provided statistical expertise. MJ participated in interpreting results, reviewing drafts of the manuscript and approved the final version of the manuscript submitted for publication.

\section{Acknowledgements}

This work was supported by the National Research Foundation of Korea Grant funded by the Korean Government (NRF-2014S1A5A8012122; PI: Prof. Dr. Minsoo Jung).

\section{Role of study sponsor}

The National Research Foundation of Korea was the study sponsor. The researcher was independent of the study sponsor.

Received: 17 October 2015 Accepted: 27 April 2016

Published online: 13 May 2016

References

1. World Health Organization. WHO Report on the Global Tobacco Epidemic, 2009. Physician's smoke-free Canada-Picture Based Cigarette Warnings. Ottawa, ON: Canadian Cancer Society; 2008. 
2. Jung M. Content analysis of smoking scenes in Korean box-office hits in 2000-2013. Korean J Health Educ Promot. 2014;31:27-40.

3. Ministry for Health and Welfare. A Survey of Smoking Behavior in 2010. Ministry for Health and Welfare of Korea, 2011. Retrieved April 30, 2011, from http://www.nosmokeguide.or.kr/mbs/nosmokeguide/jsp/board/list. jsp?boardld=256\&listType $=01 \&$ id $=$ nosmokeguide_010501000000\&categoryld $=$ 0\&categoryDepth $={ }^{\oplus}$ Column $=2010 \&$ column $=$ TITLE\&search $=$. Accessed 5 Apr 2016.

4. National Cancer Center. Nonsmoking Guide. National Cancer Center of Korea, 2014. Retrieved May 30, 2014, from http://www.nosmokeguide.or.kr/ mbs/nosmokeguide/subview.jsp?id=nosmokeguide_040101010000. Accessed 10 Apr 2016

5. Yeon JW, Kim H, Lee K, et al. Factors affecting preparation stage to quit smoking in men. J Korean Acad Nurs. 2012;42:377-84.

6. Hammond D. Tobacco packaging and labeling policies under the U.S. Tobacco Control Act: research needs and priorities. Nicotine Tob Res. 2012;14:62-74.

7. Abdullah AS, Mak YW, Loke AY, Lam TH. Smoking cessation intervention in parents of young children: A randomised controlled trial. Addiction. 2005;100: 1731-40.

8. Nakamura M, Masui S, Oshima A, Okayama A, Ueshima H, HISLIM Research Group. Effects of stage-matched repeated individual counseling on smoking cessation: A randomized controlled trial for the high-risk strategy by lifestyle modification (HISLIM) study. Environ Health Prev Med. 2004;9:152-60.

9. Marcus BH, Simkin LR, Rossi JS, Pinto BM. Longitudinal shifts in employee's stages and processes of exercise behavior change. Am J Health Promot. 1996;10:195-200.

10. Prochaska JO, DiClimente CC, Norcross JC. In search of how people change: Applications to addictive behaviors. Am Psychol. 1992;47:1102-14

11. Glanz K, Rimer BK, Viswanath K. Health behavior and health education. 4th ed. San Francisco: Jossey-Bass; 2008.

12. Marcus BH, Selby VC, Niaura RS, Rossi JS. Self-efficacy and the stages of exercise behavior change. Res Q Exer Sport. 1992;63:60-6.

13. Chang SO, Park CS. A study on the variables that influence stages of change in smoking cessation. J Korean Acad Fundam Nurs. 2001;8:391-401.

14. Ahn OH, Yeun EJ, Kwon SB, Chung HK, Ryu EJ. Predictive factors of aspects of the transtheoretical model on smoking cessation in a rural community. J Korean Acad Nurs. 2005;35:1285-94.

15. Kim HK, Park JY, Kwon EJ, Choi SH, Cho H-I. Efficacy of smoking cessation and prevention programs by intervention methods: A systematic review of published studies in Korean journals during recent 3 years. Korean J Health Educ Promot. 2013;30:61-77.

16. Kenford SL, Flore MC, Jorenby $\mathrm{DE}$, et al. Predicting smoking cessation: Who will quit with and without the nicotine patch. J Am Med Assoc. 1994;271:589-94.

17. Chang SO, Kim EJ, Kil SY, Seomun GA, Lee SJ. Influential variables on intention and action to quit smoking between adolescent smokers and adult smokers-based on the transtheoretical model. J Korean Acad Fundam Nurs. 2005:35:1410-9.

18. Son JH, Kim SA, Kam S, et al. Factors related to the intention of participation in a worksite smoking cessation program. J Prev Med Public Health. 1999;32:297-305.

19. Kim YH, Kim JS, Kim MS. Effectiveness of public health center smoking cessation counseling program using the transtheoretical model. J Korean Acad Nurs. 2009;39:469-79.

20. Chang SO, Kim EJ, Seomun GA, Lee SJ, Cha BK. Predictors of pre and post preparation in stages of change of smoking for adolescent smokers and adult smokers. J Korean Acad Fundam Nurs. 2006;13:119-28.

21. Kim YH, Seo NS, Kang HY. Nicotine dependence, smoking-related attitude, and subjective norms across the stages of change for smoking cessation among adult smokers in a rural area. J Korean Acad Nurs. 2006;36:1023-32.

22. Chang HJ, Noh MS. Factors related to the recognition and behavioral intention for smoking cessation programs. Korean J Health Educ Promot. 2003;20:1-18

23. McCloud RF, Jung M, Gray SW, Viswanath K. Class, race and ethnicity and information avoidance among cancer survivors. Br J Cancer. 2013;108:1949-56.

24. Lance CE, Butts MM, Michels LC. The sources of four commonly reported cutoff criteria: What did they really say? Org Res Method. 2006;9:202-20.

25. Berkman LF, Kawachi I. Social Epidemiology. New York, NY: Oxford University Press; 2000. p. 175

26. Sheeran P. Intention-behavior relations: A conceptual and empirical review. Eur Rev Soc Psychol. 2002;12:1-36.
27. Balmford J, Borland R, Burney S. The role of prior quitting experience in the prediction of smoking cessation. Psychol Health. 2010;25:911-24.

28. Prochaska JO, Redding CA, Harlow LL, et al. The transtheoretical model of change and HIV prevention: A review. Health Educ Q. 1994:21:471-86.

29. Prochaska JO, Velicer WF, Rossi JS, et al. Stages of change and decisional balance for 12 problem behaviors. Health Psychol. 1994;13:39-46.

30. Wu D, Ma GX, Zhou K, Zhou D, Liu A, Poon AN. The effect of a culturally tailored smoking cessation for Chinese American smokers. Nicotine Tob Res. 2009:11:1448-57.

31. Plummer BA, Velicer WF, Redding CA, et al. Stage of change, decisional balance, and temptations for smoking: Measurement and validation in a large, school-based population of adolescents. Addict Behav. 2001;26:551-71.

32. Jung $M$, Chung D. Evidence of social contextual effects on adolescent smoking in South Korea. Asia Pac J Public Health. 2013;25:260-70.

33. Christakis NA, Fowler JH. The collective dynamics of smoking in a large social network. N Engl J Med. 2008;358:2249-58.

34. Jung M, Chan CK, Viswanath K. Moderating effects of media exposure on associations between socioeconomic position and cancer worry. Asian Pac J Cancer Prev. 2014;15:5845-51.

35. Christakis NA, Fowler $\mathrm{JH}$. The spread of obesity in a large social network over 32 years. N Engl J Med. 2007;357:370-9.

36. Jung M, Arya M, Viswanath K. Effect of media use on HIV/AIDS-related knowledge and condom use in Sub-Saharan Africa: A cross-sectional study. PLoS One. 2013;8:e68359.

37. Thrul J, Klein AB, Ramo DE. Smoking Cessation Intervention on Facebook: Which Content Generates the Best Engagement? J Med Internet Res. 2015;17:e244.

38. Alcalá HE, Sharif MZ, Albert SL. Social cohesion and the smoking behaviors of adults living with children. Addict Behav. 2016;53:201-5.

39. Jung $M$, Viswanath $K$. Does community capacity influence self-rated health? Multilevel contextual effects in Seoul. Korea Soc Sci Med. 2013;77:60-9.

\section{Submit your next manuscript to BioMed Central and we will help you at every step:}

- We accept pre-submission inquiries

- Our selector tool helps you to find the most relevant journal

- We provide round the clock customer support

- Convenient online submission

- Thorough peer review

- Inclusion in PubMed and all major indexing services

- Maximum visibility for your research

Submit your manuscript at www.biomedcentral.com/submit
) Biomed Central 